\title{
The use of reductants in oxidation degumming of ramie
}

\begin{abstract}
When ramie fiber was extracted by oxidation degumming, large amount of hydroxyl groups were converted to carboxyl groups and aldehydes groups. This would do great damage to tensile properties of fiber, for the hydrogen bonds among carboxyl groups and aldehydes groups were much weaker than the ones among hydroxyl groups. In this study, tensile properties of fiber extracted by oxidation degumming were improved by reducing the fiber in solutions containing reductants. Three kinds of reductants, including thiourea dioxide, vitamin $\mathrm{C}$, sodium hydrosulfite, were investigated in this study and $\mathrm{L}_{9}\left(3^{4}\right)$ orthogonal design was used to find the optimal reaction condition for each reductant. Results showed that thiourea dioxide and sodium hydrosulfite should be used under the $\mathrm{pH}$ value of 11.0 12.0; and vitamin $\mathrm{C}$ should be used under the $\mathrm{pH}$ value of 6.0 7.0. The optimal reaction condition for thiourea dioxide, vitamin $\mathrm{C}$, sodium hydrosulfite, were $6 \%, 100^{\circ} \mathrm{C}, 20 \mathrm{~min} ; 6 \%, 20^{\circ} \mathrm{C}, 20 \mathrm{~min} ; 6 \%, 100^{\circ} \mathrm{C}, 20 \mathrm{~min}$, respectively. After reducing in thiourea dioxide, vitamin $\mathrm{C}$, sodium hydrosulfite solutions, and the tensile strength of fiber increased by $29.08 \%, 27.86 \%, 3.2 \%$, respectively.
\end{abstract}

Keywords: ramie fiber, oxidation degumming, reductants, tensile property
Volume 2 Issue 6 - 2017

\author{
Chaoran Meng, ${ }^{1,2}$ Chongwen Yu, ${ }^{1,2,3}$ \\ 'College of Textiles, Donghua University, Shanghai, China \\ ${ }^{2}$ Key Laboratory of Textile Science \& Technology, Ministry of \\ Education, China \\ ${ }^{3}$ Insititute of Bast Fiber Crops, Chinese academy of agricultural \\ sciences, China
}

\begin{abstract}
Correspondence: Chongwen Yu, College of Textiles, Donghua University, Key Laboratory of Textile Science \& Technology, Ministry of Education, Shanghai, 201620, Institute of Bast Fiber Crops, Chinese academy of agricultural sciences, Changsha, Hunan, China, Tel I3651603285, Email yucw@dhu.edu.cn
\end{abstract}

Received: July 27, 2017 | Published: August 31, 2017

\section{Introduction}

Ramie is a perennial herb whose fiber could be used as excellent materials for clothing fabrics, fiber reinforced composites, car accessories, ect. ${ }^{1,2}$ In China, ramie is one of the main economic crops; the production of ramie in China has accounted more than $90 \%$ of the total yield in the world. ${ }^{3}$ The production made of ramie fiber possesses many excellent properties, such as high moisture absorption capacity, good thermal conductivity, outstanding antibacterial function and favorable air permeability. ${ }^{4,5}$ Cellulose is the main component of ramie fiber, while the other components in ramie, such as pectin, lignin, water soluble, etc, are defined as gums. ${ }^{6}$ Degumming refers to the removal of heavily coated gummy material from the cellulosic part of plant fiber, and it is necessary prior to further spinning process. ${ }^{7}$ There were mainly two approaches of ramie degumming, namely, traditional chemical degumming and bio-degumming. ${ }^{8}$ The energy and time consumption, chemical oxygen demand (COD value) of degumming wastewater in traditional chemical degumming was rather high, for cellulose fiber was extracted by scouring raw ramie in concentrated $\mathrm{NaOH}$ under high pressure for $6 \mathrm{~h}$ to $8 \mathrm{~h} .{ }^{9} \mathrm{Bio}-$ degumming is an ecofriendly way of ramie fiber extraction; however, the harsh reaction condition and sophisticated equipment inhibited its further industrial application. ${ }^{10}$ Under this circumstance, novel chemical degumming method 'oxidation degumming' showed good application foreground, for it can get high degumming yield under low energy consumption in only $4 h .^{8}$

Compared with traditional degumming, oxidation degumming with $\mathrm{H}_{2} \mathrm{O}_{2}$ is effective, eco-friendly, and of high fiber yield. ${ }^{9} \mathrm{H}_{2} \mathrm{O}_{2}$ can decompose into several kinds of free radicals (such as $\mathrm{O}_{2}^{-} \cdot$, $\mathrm{OH} \cdot \mathrm{OOH} \cdot \mathrm{OH}^{-}$, ect) in alkali condition, these radicals have strong oxidizing ability. The gummy materials have a relatively lower degree of polymerization and crystallinity which is easily attacked by these radicals and are easily dissolved in degumming solution. However, cellulose can resist alkaline condition, thus it can be separated from raw ramie. ${ }^{10}$ Due to the strong oxidation ability of the peroxides degumming solution, great amount of cellulose degradation may occur during the degumming process and large proportion of hydroxyl groups in cellulose were converted to acid groups (carboxyl groups and aldehyde groups), which would cause great damage to fiber properties. ${ }^{11}$ In order to address this issue, oxidation degumming has been extensively studied for many years. Liu ${ }^{10}$ improved tensile properties of oxidation degummed ramie fiber by adding $\mathrm{H}_{2} \mathrm{O}_{2}$ stabilizer in degumming solution. Meng ${ }^{12}$ protected cellulose successfully by adding anthraquinone in degumming solution. $\mathrm{Li}^{13}$ controlled the decomposition speed of $\mathrm{H}_{2} \mathrm{O}_{2}$ by multiple feeding $\mathrm{NaOH}$ and $\mathrm{H}_{2} \mathrm{O}_{2}$ in degumming solution. However, most of these methods focused on preventing cellulose from degradation, the study on acid groups were seldom studied. $\mathrm{Li}^{14}$ tried to convert the acid groups in oxidation degummed ramie fiber back to hydroxyl groups by reducing the fiber in $\mathrm{NaH}_{4} \mathrm{~B}$ solution, and results showed that this process was very helpful in improving the tensile properties of fiber, However, this important process has not been studied sufficiently yet.

In this paper, several kinds of reductants, including vitamin $\mathrm{C}$, sodium hydrosulfite, thiourea dioxide, and sodium hydrogen sulfite was used in oxidation degumming of ramie. The optimal reaction condition of these reductants was studied respectively and the properties of fiber reduced by various reductants were compared.

\section{Experiment}

\section{Materials}

In this experiment, the raw ramie was obtained from Changde, Hunan Province, China. The chemical composition of the ramie material was tested and listed in Table 1.

\section{Chemicals}

The main chemicals used in this study were $\mathrm{H}_{2} \mathrm{O}_{2}, \mathrm{NaOH}$, 
$\mathrm{Na}_{5} \mathrm{P}_{3} \mathrm{O}_{10}, \mathrm{HEDP}$, vitamin $\mathrm{C}\left(\mathrm{C}_{6} \mathrm{H}_{8} \mathrm{O}_{6}\right)$, sodium hydrosulfite $\left(\mathrm{Na}_{2} \mathrm{O}_{4} \mathrm{~S}_{2}\right)$, thiourea dioxide $\left(\mathrm{CH}_{4} \mathrm{~N}_{2} \mathrm{O}_{2} \mathrm{~S}\right)$, which were purchased from Sinopharm Chemical Reagent Co. Ltd (Shanghai, China). All chemicals used in this study were analytical grade.

\section{Process for the degumming of ramie}

Degumming solution was composed of $6 \%$ (o.w.f) $\mathrm{H}_{2} \mathrm{O}_{2}, 10 \%$ (o.w.f) $\mathrm{NaOH}, 4 \%$ (o.w.f) $\mathrm{Na}_{5} \mathrm{P}_{3} \mathrm{O}_{10}, 2 \%$ HEDP, with a liquor ration of 1:10. Raw ramie was immersed in the degumming solution, and scoured under the temperature of $85^{\circ} \mathrm{C}$ for 60 minutes. Then the temperature was raised to $125^{\circ} \mathrm{C}$ (with pressure of $0.6 \mathrm{~kg}$ ), and kept for another 60 minutes.

Subsequently, the treated fibers were immersed in solution composed of various reductants for the reducing process. $\mathrm{L}_{9}\left(3^{4}\right)$ orthogonal design was used to investigate the optimal reaction condition for thiourea dioxide (Table 2), vitamin C (Table 3), sodium hydrosulfite (Table 4).

Finally, the fiber was washed thoroughly with distilled water and properly dried at oven $\left(100^{\circ} \mathrm{C}, 3 \mathrm{~h}\right)$ for the subsequent characterization.

Table I Chemical composition of raw ramie

\begin{tabular}{llllllll}
\hline Ingredient & Cellulose & Hemicellulose & Pectin & Lignin & Wax & Ash & Water solubles \\
\hline Content (\%) & 74.25 & 13.8 & 5.16 & 1.3 & 1.04 & 1.05 & 3.4 \\
\hline
\end{tabular}

Table 2 Variables and levels of orthogonal design of $\mathrm{CH} 4 \mathrm{~N} 2 \mathrm{O} 2 \mathrm{~S}$

\begin{tabular}{llll}
\hline Levels & Dosage (\%) & Temperature $\left({ }^{\circ} \mathbf{C}\right)$ & Time (min) \\
\hline 1 & 2 & 60 & 20 \\
2 & 4 & 80 & 40 \\
3 & 6 & 100 & 60 \\
\hline
\end{tabular}

Table 3 Experimental range and levels of independent variables of Vitamin C

\begin{tabular}{llll}
\hline Levels & Dosage (\%) & Temperature $\left({ }^{\circ} \mathbf{C}\right)$ & Time (min) \\
\hline 1 & 2 & 20 & 20 \\
2 & 4 & 40 & 40 \\
3 & 6 & 60 & 60 \\
\hline
\end{tabular}

Table 4 Variables and levels of orthogonal design of $\mathrm{Na}_{2} \mathrm{O}_{4} \mathrm{~S}_{2}$

\begin{tabular}{llll}
\hline Levels & Dosage (\%) & Temperature $\left({ }^{\circ} \mathbf{C}\right)$ & Time $(\mathbf{m i n})$ \\
\hline 1 & 2 & 60 & 20 \\
2 & 4 & 80 & 40 \\
3 & 6 & 100 & 60 \\
\hline
\end{tabular}

\section{Mechanical property test}

Fibers samples were conditioned in standard atmospheric condition $\left(\mathrm{T}=20^{\circ} \mathrm{C} \pm 2^{\circ} \mathrm{C}, \mathrm{RH}=65 \% \pm 2 \%\right.$ ) for $24 \mathrm{~h}$ before the mechanical test. Breaking strength, breaking elongation was tested using a XQ-2 fiber strength instrument under the condition of $20^{\circ} \mathrm{C}$ and $\mathrm{RH} 65 \%$. The pretension was $0.3 \mathrm{cN} / \mathrm{dtex}$. The clamping distance was set with $20 \mathrm{~mm}$, and the descending speed of the bottom clamp was $20 \mathrm{~mm} / \mathrm{min}$.

\section{ORP value}

Oxidation reduction potential (ORP) $)^{13}$ is an important water chemistry parameter and it provides a measurement tool for oxidizing or reducing capacity of the ambient water. ORP is measured in volts $(\mathrm{V})$ or millivolts $(\mathrm{mV})$ with oxidation-reduction potentiometer. The more positive the potential value, the greater the species' affinity for electrons and tendency to oxidize.

The relationship between ORP and the concentrations of the oxidized and reduced forms of a substance is given by Nernst Equation (1),

$$
E_{h}=E_{0}+\frac{2.303 R T}{n F} \log \frac{\left[o_{x}\right]}{[\operatorname{Re} d]}
$$

Where $E_{h}$ is the potential at the standard hydrogen electrode $(\mathrm{mV})$, $E_{0}$ is the standard potential of the system when the activities of all reactants are unity, $\mathrm{R}$ is the universal gas constant $\left(8.314 \mathrm{JK}^{-1} / \mathrm{mol}\right)$, $\mathrm{T}$ is the absolute temperature in Kelvin, $\mathrm{F}$ is the Faraday constant $\left(96.5 \mathrm{JK}^{-1 /} \mathrm{mol}\right), \mathrm{n}$ is the number of electrons involved in reaction, $\left[O_{x}\right]$ is the chemical activity for the oxidant, $[R e d]$ is the chemical activity for the reluctant.

In this experiment, the ORP value of the degumming solution were also determined and monitored by MODEL 421 ORP meter (Dapu Instrument, Shanghai, China).

\section{Results and discussion \\ The reducing ability of reductants}

ORP values reflected the comprehensive oxidation ability of degumming solution. Solutions with positive ORP values exhibited oxidability and solution with stronger oxidability got higher ORP values; solutions with negative ORP values exhibited reducibility and solution with stronger reducibility got higher absolute ORP values.

It was wildly known that the reducibility of reductants vary with their $\mathrm{pH}$ value of solution, in order to searching for the optimal $\mathrm{pH}$ values for reducing reaction, the ORP values of reducing solution composed of $2 \%$ (o.w.f.) $\mathrm{CH}_{4} \mathrm{~N}_{2} \mathrm{O}_{2} \mathrm{~S}, 2 \%$ (o.w.f.) $\mathrm{Na}_{2} \mathrm{O}_{4} \mathrm{~S}_{2}$ and $2 \%$ (o.w.f.) $\mathrm{C}_{6} \mathrm{H}_{8} \mathrm{O}_{6}$ was tested respectively (Table 5). It was obvious from Table 5, the ORP value of $\mathrm{CH}_{4} \mathrm{~N}_{2} \mathrm{O}_{2} \mathrm{~S}$ solution was $-120 \mathrm{mV}$ under the $\mathrm{pH}$ value of $7.0 \sim 8.0$, however, the ORP value decreased to $-720 \mathrm{mV}$ under the $\mathrm{pH}$ value of $11.0 \sim 12.0$. It could be deduced that $\mathrm{pH}$ value have strong influence on the reducibility of $\mathrm{CH}_{4} \mathrm{~N}_{2} \mathrm{O}_{2} \mathrm{~S}$ and this reductant should be used under alkali condition. The ORP value of $\mathrm{Na}_{2} \mathrm{O}_{4} \mathrm{~S}_{2}$ solution was $-540 \mathrm{mV}$ under the $\mathrm{pH}$ value of $7.0 \sim 8.0$ and decreased to $-650 \mathrm{mV}$ under the $\mathrm{pH}$ value of $11.0 \sim 12.0$, which proved that $\mathrm{pH}$ value showed some influence on the reducibility of $\mathrm{Na}_{2} \mathrm{O}_{4} \mathrm{~S}_{2}$ and it should be used under alkali condition. $\mathrm{C}_{6} \mathrm{H}_{8} \mathrm{O}_{6}$ can only be used under $\mathrm{pH}$ value of 6.0 7.0, for $\mathrm{C}_{6} \mathrm{H}_{8} \mathrm{O}_{6}$ was easily to be damaged under alkali condition. The ORP value of $\mathrm{C}_{6} \mathrm{H}_{8} \mathrm{O}_{6}$ solution was $-100 \mathrm{mV}$. 
The effect of various reductants on tensile property of fiber

Sodium hydrosulfite: $\mathrm{L}_{9}\left(3^{4}\right)$ orthogonal design was used to investigate the optimal reaction condition of $\mathrm{CH}_{4} \mathrm{~N}_{2} \mathrm{O}_{2} \mathrm{~S}$, and the results of tensile properties were shown in Table 6. Tensile strength of fiber increased with $\mathrm{CH}_{4} \mathrm{~N}_{2} \mathrm{O}_{2} \mathrm{~S}$ dosage, reaction temperature and reaction time (Figure 1a), for the reducibility of $\mathrm{CH}_{4} \mathrm{~N}_{2} \mathrm{O}_{2} \mathrm{~S}$ solution was strongly boosted under such condition. Tensile elongation of fiber increased with $\mathrm{CH}_{4} \mathrm{~N}_{2} \mathrm{O}_{2} \mathrm{~S}$ dosage, reaction temperature and reaction time, from $2 \% \sim 4 \%, 60^{\circ} \mathrm{C} \sim 80^{\circ} \mathrm{C}, 20 \mathrm{~min} \sim 40 \mathrm{~min}$; further increase of these parameters would cause decrease of fiber elongation (Figure 1b), which indicated relatively mild reaction condition was good for improving elongation of fiber. ANOVA analysis (Table 7) revealed that $\mathrm{CH}-$ ${ }_{4} \mathrm{~N}_{2} \mathrm{O}_{2} \mathrm{~S}$ dosage, reaction temperature and reaction time had significant effect on tensile strength of fiber; however, these three parameters did not have significant effect on tensile elongation of fiber. Therefore, when tensile properties and degumming efficient was both taken into consideration, the optimal reaction condition of $\mathrm{CH}_{4} \mathrm{~N}_{2} \mathrm{O}_{2} \mathrm{~S}$ was $6 \%$, $100^{\circ} \mathrm{C}, 20 \mathrm{~min}$.

Vitamin C: $\mathrm{L}_{9}\left(3^{4}\right)$ orthogonal design was used to investigate the optimal reaction condition of vitamin $\mathrm{C}$, and the results of tensile properties were shown in Table 8. Tensile strength of fiber increased with Vitamin $\mathrm{C}$ dosage and decreased with reaction temperature, however, reaction time did not show much influence on tensile strength. That was because the efficiency and speed of reducing reaction of vitamin $\mathrm{C}$ was high; however, vitamin $\mathrm{C}$ was easily destroyed under higher temperature (Figure 2a). Tensile elongation of fiber increased

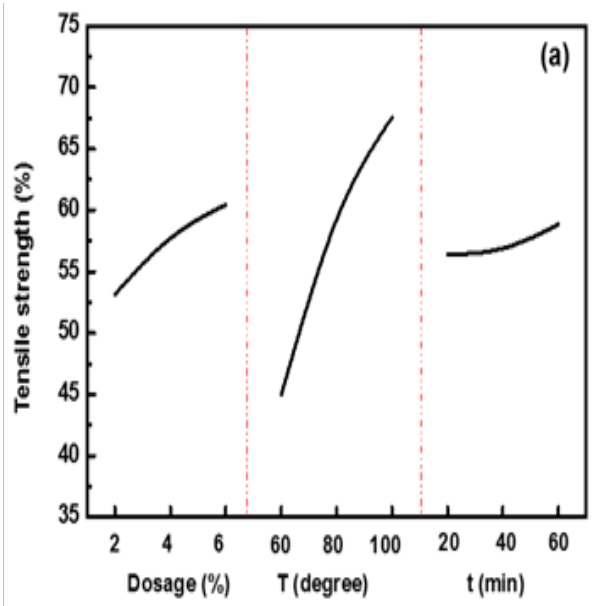

Figure I The effect of $\mathrm{CH}_{4} \mathrm{~N}_{2} \mathrm{O}_{2} \mathrm{~S}$ dosage, reaction temperature and reaction time on tensile properties of fiber: (A) Strength; (B) Elongation of fiber.

\section{Comparison of the three reductants}

In order to compare the effect of these reductants, ramie fiber was reduced in thiourea dioxide $\left(6 \%, 100^{\circ} \mathrm{C}, 20 \mathrm{~min}\right)$, vitamin $\mathrm{C}\left(6 \%, 20^{\circ} \mathrm{C}\right.$, $20 \mathrm{~min})$, sodium hydrosulfite on fiber property $\left(6 \%, 100^{\circ} \mathrm{C}, 20 \mathrm{~min}\right)$, and the results were shown in Table 12. It was obvious that the fiber reduced with thiourea dioxide and sodium hydrosulfite got similar tensile properties, which was $\%$ and $\%$ higher than that reduced with vitamin $\mathrm{C}$. That was because the reductivity of vitamin $\mathrm{C}$ was not as strong as thiourea dioxide and sodium hydrosulfite, moreover, vitamin $\mathrm{C}$ tended to loss its activity because of the metal ions existed in the degumming solution. After reducing in thiourea dioxide, vitamin $\mathrm{C}$, sodium hydrosulfite solutions, and the tensile strength of fiber increased by $29.08 \%, 27.86 \%, 3.2 \%$, respectively.

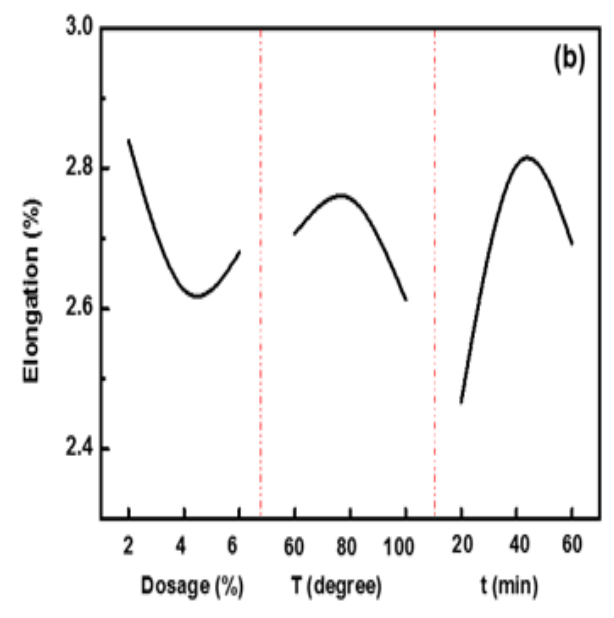

with vitamin $\mathrm{C}$ dosage, reaction temperature and reaction time, from $2 \% \sim 4 \%, 20^{\circ} \mathrm{C} \sim 60^{\circ} \mathrm{C}, 20 \mathrm{~min} \sim 40 \mathrm{~min}$; further increase of these parameters would cause decrease of fiber elongation (Figure $2 b$ ), which indicated relatively mild reaction condition was good for improving elongation of fiber. ANOVA analysis (Table 9) revealed that vitamin $\mathrm{C}$ dosage, reaction temperature had significant effect on tensile strength of fiber, and however, all of the three parameters did not have significant effect on tensile elongation of fiber. Therefore, when fiber property and degumming efficient was both taken into consideration, the optimal reaction condition of vitamin $\mathrm{C}$ was $6 \%, 20^{\circ} \mathrm{C}, 20 \mathrm{~min}$.

Sodium hydrosulfite: $\mathrm{L}_{9}\left(3^{4}\right)$ orthogonal design was used to investigate the optimal reaction condition of $\mathrm{Na}_{2} \mathrm{O}_{4} \mathrm{~S}_{2}$, and the results of tensile properties were shown in Table 10. Tensile strength of fiber increased with $\mathrm{Na}_{2} \mathrm{O}_{4} \mathrm{~S}_{2}$ dosage and reaction temperature, however, reaction time did not show much influence on tensile strength, for the reducibility of $\mathrm{Na}_{2} \mathrm{O}_{4} \mathrm{~S}_{2}$ solution was strongly boosted under such condition (Figure 3a). Tensile elongation of fiber increased with $\mathrm{Na}_{2} \mathrm{O}_{4} \mathrm{~S}_{2}$ dosage, reaction temperature and reaction time, from $2 \% \sim 4 \%, 60^{\circ} \mathrm{C} \sim 80^{\circ} \mathrm{C}$, $20 \mathrm{~min} \sim 40 \mathrm{~min}$; further increase of these parameters would cause decrease of fiber elongation (Figure $3 \mathrm{~b}$ ), which indicated relatively mild reaction condition was good for improving elongation of fiber. ANOVA analysis (Table 11) revealed that $\mathrm{Na}_{2} \mathrm{O}_{4} \mathrm{~S}_{2}$ dosage, reaction temperature had significant effect on tensile strength of fiber, and however, all of the three parameters did not have significant effect on tensile elongation of fiber. Therefore, when fiber property and degumming efficient was both taken into consideration, the optimal reaction condition of $\mathrm{Na}_{2} \mathrm{O}_{4} \mathrm{~S}_{2}$ was $6 \%, 100^{\circ} \mathrm{C}, 20 \mathrm{~min}$.

Table 5 The reducing ability of reductants

\begin{tabular}{lll}
\hline & ph value & Orp value \\
\hline $\mathrm{CH}_{4} \mathrm{~N}_{2} \mathrm{O}_{2} \mathrm{~S}$ & $7.0 \sim 8.0$ & -120 \\
& $11.0 \sim 12.0$ & -720 \\
$\mathrm{Na}_{2} \mathrm{O}_{4} \mathrm{~S}_{2}$ & $7.0 \sim 8.0$ & -540 \\
& $11.0 \sim 12.0$ & -650 \\
$\mathrm{NaHSO}_{3}$ & $7.0 \sim 8.0$ & -140 \\
$\mathrm{C}_{6} \mathrm{H}_{8} \mathrm{O}_{6}$ & $11.0 \sim 12.0$ & -140 \\
\hline
\end{tabular}



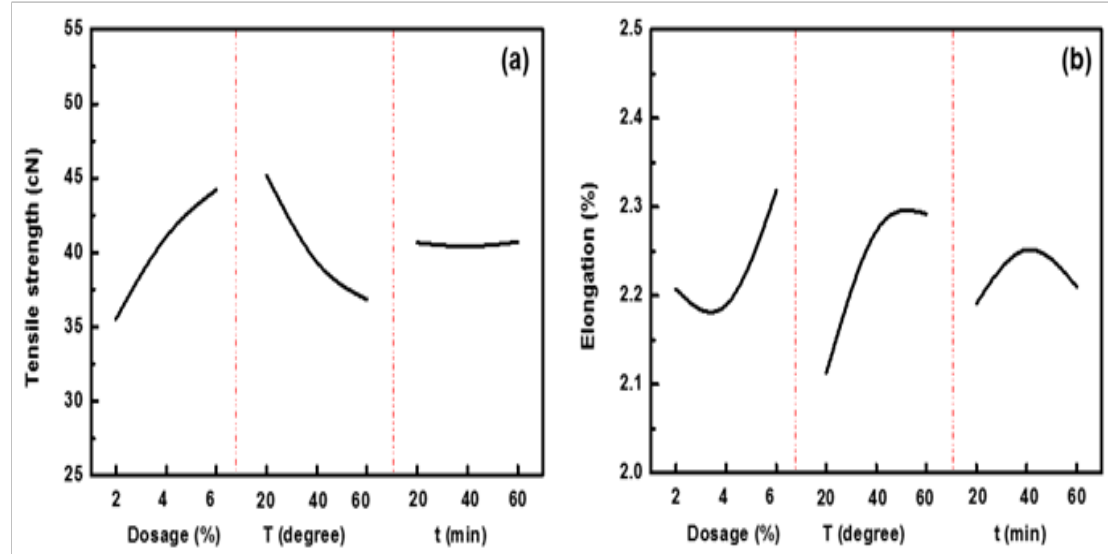

Figure 2 The effect of Vitamin $C$ dosage, reaction temperature and reaction time on tensile properties of fiber: (A) Strength; (B) Elongation of fiber.
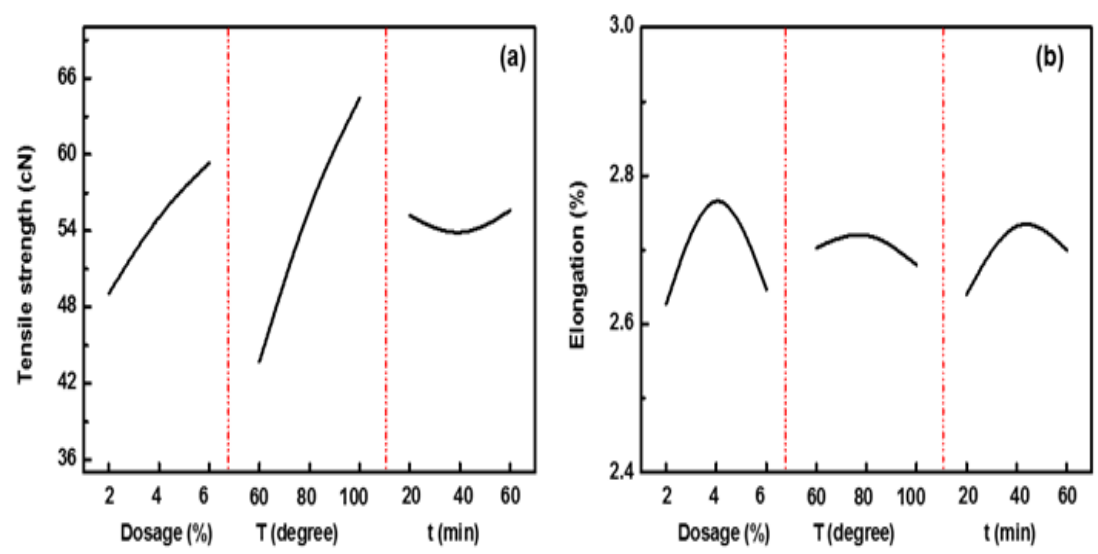

Figure 3 The effect of Vitamin $C$ dosage, reaction temperature and reaction time on tensile properties of fiber: (A) Strength; (B) Elongation of fiber.

Table 6 Tensile strength and elongation of fiber in orthogonal design of $\mathrm{CH}_{4} \mathrm{~N}_{2} \mathrm{O}_{2} \mathrm{~S}$

\begin{tabular}{llllll}
\hline S.no & Dosage (\%) & ${\text { Temperature }\left({ }^{\circ} \mathbf{C}\right)}$ & Time $(\mathbf{m i n})$ & Tensile strength $(\mathbf{c N})$ & Tensile elongation $(\%)$ \\
\hline 1 & 1 & 1 & 1 & 38.37 & 2.66 \\
2 & 1 & 2 & 2 & 54.82 & 3.24 \\
3 & 1 & 3 & 3 & 66.26 & 2.61 \\
4 & 2 & 1 & 3 & 46.37 & 2.65 \\
5 & 2 & 2 & 1 & 60.15 & 2.66 \\
6 & 2 & 3 & 2 & 68 & 2.37 \\
7 & 3 & 1 & 2 & 50.14 & 2.81 \\
8 & 3 & 2 & 3 & 62.84 & 2.37 \\
9 & 3 & 3 & 1 & 68.39 & 2.86 \\
\hline
\end{tabular}

Table 7 The ANOVA analysis of orthogonal design of $\mathrm{CH}_{4} \mathrm{~N}_{2} \mathrm{O}_{2} \mathrm{~S}$

\begin{tabular}{|c|c|c|c|c|c|c|c|c|c|c|}
\hline & \multicolumn{5}{|c|}{ Tensile strength (cN) } & \multicolumn{5}{|c|}{ Elongation (\%) } \\
\hline & SS & Df & $\mathbf{F}$ & $F_{0.05(2,2)}$ & $\mathbf{s}$ & SS & Df & $\mathbf{F}$ & $F_{0.05(2,2)}$ & $\mathbf{S}$ \\
\hline $\mathrm{D}(\%)$ & 146.39 & 2 & 377.29 & 19 & $*$ & 0.12 & 2 & 1.06 & 19 & \\
\hline $\mathrm{T}\left({ }^{\circ} \mathrm{C}\right)$ & 964.73 & 2 & 2486.42 & 19 & $*$ & 0.03 & 2 & 0.29 & 19 & \\
\hline $\mathrm{t}(\mathrm{min})$ & 22.84 & 2 & 58.86 & 19 & $*$ & 0.3 & 2 & 2.79 & 19 & \\
\hline Error & 0.39 & 2 & & & & 0.11 & 2 & & & \\
\hline
\end{tabular}


Table 8 Tensile strength and elongation of fiber in orthogonal design of Vitamin C

\begin{tabular}{llllll}
\hline S.no & Dosage (\%) & Temperature $\left({ }^{\circ} \mathbf{C}\right)$ & Time $(\mathbf{m i n})$ & Tensile strength $(\mathbf{c N})$ & Tensile elongation (\%) \\
\hline 1 & 1 & 1 & 1 & 40.14 & 2.076 \\
2 & 1 & 2 & 2 & 34.28 & 2.262 \\
3 & 1 & 3 & 3 & 32.13 & 2.284 \\
4 & 2 & 1 & 3 & 46.43 & 2.117 \\
5 & 2 & 2 & 1 & 40.25 & 2.201 \\
6 & 2 & 3 & 2 & 38.26 & 2.14 \\
7 & 3 & 1 & 2 & 48.95 & 2.146 \\
8 & 3 & 2 & 3 & 43.55 & 2.357 \\
9 & 3 & 3 & 1 & 40.18 & 2.451 \\
\hline
\end{tabular}

Table 9 The ANOVA analysis of orthogonal design of Vitamin C

\begin{tabular}{lllllllllll}
\hline & \multicolumn{1}{c}{ Tensile strength (cN) } & \multicolumn{7}{c}{ Elongation (\%) } \\
\cline { 2 - 10 } & SS & Df & $\mathbf{F}$ & $\mathbf{F}_{0.05(2,2)}$ & $\mathbf{S}$ & $\mathbf{S S}$ & $\mathbf{D f}$ & $\mathbf{F}$ & $\mathbf{F}_{0.05(2,2)}$ \\
\hline $\mathrm{D}(\%)$ & 120.1 & 2 & 300.24 & 19 & $*$ & 0.043 & 2 & 4.78 & 19 \\
$\mathrm{~T}\left({ }^{\circ} \mathrm{C}\right)$ & 109.23 & 2 & 273.07 & 19 & $*$ & 0.058 & 2 & 6.44 & 19 \\
$\mathrm{~T}(\mathrm{~min})$ & 0.19 & 2 & 0.47 & 19 & & 0.012 & 2 & 1.33 & 19 \\
Error & 0.4 & 2 & & & 0.01 & 2 & & \\
\hline
\end{tabular}

Table 10 Tensile strength and elongation of fiber in orthogonal design of $\mathrm{Na}_{2} \mathrm{O}_{4} \mathrm{~S}_{2}$

\begin{tabular}{llllll}
\hline S.No & Dosage (\%) & Temperature $\left({ }^{\circ} \mathbf{C}\right)$ & Time $(\mathbf{m i n})$ & Tensile strength $(\mathbf{c N})$ & Tensile elongation (\%) \\
\hline 1 & 1 & 1 & 1 & 38.38 & 2.75 \\
2 & 1 & 2 & 2 & 48.75 & 2.66 \\
3 & 1 & 3 & 3 & 60.14 & 2.47 \\
4 & 2 & 1 & 3 & 43.37 & 2.76 \\
5 & 2 & 2 & 1 & 57.23 & 3.03 \\
6 & 2 & 3 & 2 & 65.89 & 2.7 \\
7 & 3 & 1 & 2 & 49.44 & 2.6 \\
8 & 3 & 2 & 3 & 61.4 & 2.47 \\
9 & 3 & 3 & 1 & 67.23 & 2.87 \\
\hline
\end{tabular}

Table I I The ANOVA analysis of orthogonal design of $\mathrm{Na}_{2} \mathrm{O}_{4} \mathrm{~S}_{2}$

\begin{tabular}{|c|c|c|c|c|c|c|c|c|c|c|}
\hline & \multicolumn{5}{|c|}{ Tensile Strength (cN) } & \multicolumn{5}{|c|}{ Elongation (\%) } \\
\hline & SS & Df & $\mathbf{F}$ & $\mathbf{F}_{0.05(2,2)}$ & $\mathbf{S}$ & SS & Df & $\mathbf{F}$ & $F_{0.05(2,2)}$ & $\mathbf{S}$ \\
\hline D (\%) & 161.35 & 2 & 223.17 & 19 & $*$ & 0.0075 & 2 & 0.466 & 19 & 0 \\
\hline $\mathrm{T}\left({ }^{\circ} \mathrm{C}\right)$ & 648.02 & 2 & 896.29 & 19 & $*$ & 0.002 & 2 & 0.012 & 19 & 0 \\
\hline$t(\min )$ & 10.77 & 2 & 14.89 & 19 & & 0.023 & 2 & 0.143 & 19 & 0 \\
\hline Error & 0.72 & 2 & & & & 0.16 & 2 & & & 0 \\
\hline
\end{tabular}


Table I 2 Tensile properties of fiber reduced with thiourea dioxide, vitamin C, and sodium hydrosulfite

\begin{tabular}{lll}
\hline & $\begin{array}{l}\text { Tensile strength } \\
(\mathbf{c N})\end{array}$ & $\begin{array}{l}\text { Tensile elongation } \\
(\%)\end{array}$ \\
\hline Thiourea Dioxide & 68.39 & 2.86 \\
Sodium Hydrosulfite & 67.23 & 2.87 \\
Vitamin C & 50.11 & 2.2 \\
Before reducing & 48.5 & 2.1 \\
\hline
\end{tabular}

\section{Conclusion}

In this study, tensile properties of fiber extracted by oxidation degumming were improved by reducing the fiber in solutions containing reductants. Three kinds of reductants, including thiourea dioxide, vitamin $\mathrm{C}$, sodium hydrosulfite, were investigated in this study and $\mathrm{L}_{9}\left(3^{4}\right)$ orthogonal design was used to find the optimal reaction condition for each reductant. Results showed that thiourea dioxide and sodium hydrosulfite should be used under the $\mathrm{pH}$ value of 11.0 12.0; and vitamin $\mathrm{C}$ should be used under the $\mathrm{pH}$ value of 6.0 7.0. The optimal reaction for thiourea dioxide, vitamin $\mathrm{C}$, sodium hydrosulfite, was $6 \%, 100^{\circ} \mathrm{C}, 20 \mathrm{~min} ; 6 \%, 20^{\circ} \mathrm{C}, 20 \mathrm{~min} ; 6 \%, 100^{\circ} \mathrm{C}$, $20 \mathrm{~min}$, respectively. After reducing in thiourea dioxide, vitamin $\mathrm{C}$, sodium hydrosulfite solutions, and the tensile strength of fiber increased by $29.08 \%, 27.86 \%, 3.2 \%$, respectively. That was because the carboxyl groups and aldehyde groups in cellulose were reduced to hydroxyl groups, which can generate stronger hydrogen bonds and thus improve the tensile properties of fiber.

\section{Acknowledgments}

The authors acknowledge the financial support from the earmarked fund for China Agriculture Research System for Bast and Leaf Fiber Crops: CARS-19.

China Academy of Agricultural Science and Technology Innovation Project: ASTIP-IBFC07.

The innovation fund for graduate students in Donghua University: $16 \mathrm{D} 310107$.

\section{Conflict of interest}

Author declares there is no conflict of interest.

\section{References}

1. Omar F, Andrzej KB, Hans-Peter F, et al. Bio composites reinforced with natural fiber: 2000-2010. Prog Polym Sci. 2012;37(11):1552-1596.

2. Yuan J, Yu Y, Wang Q, et al. Modification of ramie with 1-butyl-3-methylimidazolium Chloride Ionic Liquid. Fibers \& Polymers. 2013;14(8):1254-1260.

3. Choi HY, Lee JS. Effect of surface treatment of ramie fiber in a ramie/ poly (lactic acid) composite. Fiber Polym. 2012;13(2):217-223.

4. Ramamoorthy SK, Skrifvars M, Persson A. A Review of Natural Fiber Used in Bio composites: Plant, Animal and Regenerated Cellulose Fiber. Polymer Reviews. 2015;55(1):107-162

5. Zhaoling Li, Chen J, Zhou J, et al. High-efficiency ramie fiber degumming and self-powered degumming wastewater treatment using triboelectric nano generator. Nano Energ. 2016;22:548-557.

6. Zhaoling Li, Meng C, Yu C. Analysis of oxidized cellulose introduced into ramie fiber by oxidation degumming. Textile Research $J$. 2015;85(20):2125-2135.

7. Fanchang Jiang. Spinning of ramie fiber. Textile Industry Press of China, Beijing, China; 1986.

8. Guoliang Liu. Research on the application of sodium per carbonate the degumming of ramie. Dissertation, Donghua University, China; 2013.

9. Chaoran Meng, Li Z, Wang C, et al. Sustained-release Alkali Source Used in the Oxidation Degumming of Ramie. Text Res J. 2017;87(10):1155-1164.

10. Chaoran Meng, Yu C. Study on the oxidation degumming of ramie fiber. Advanced Materials Research. 2014;881-883:1497-1500.

11. Zhaoling Li. Mechanism analysis of ramie oxidation degumming and self-power degumming wastewater treatment. Dissertation, Donghua University, China; 2015.

12. Chaoran Meng, Liu F, Li Z, et al. The cellulose protection agent used in the oxidation degumming of ramie. Textile Research $J$. 2016;86(10):1109-1118.

13. Zhaoling Li, Yu C. Effect of Peroxide and Softness Modifiaction on Properties of Ramie Fiber. Fiber \& Polymers. 2014;15(10):2105-2111.

14. Zhaoling Li, Meng C, Zhou J, et al. Characterization and control of oxidized cellulose in ramie fiber during oxidation degumming. Textile Research J. 2017;87(15):1828-1840. 